\title{
La agencia animal en el arte siciliano de la Edad del Hierro (ss. VIII-VI a. C.): interacciones entre bovinos y humanos ${ }^{1}$
}

\author{
Mireia López-Bertran y Meritxell Ferrer \\ Universitat de València; Universitat Pompeu Fabra \\ Mireia.Lopez@uv.es; meritxell.ferrer@upf.edu
}

RESUMEN: El objetivo del presente artículo es el análisis de las relaciones entre bovinos y humanos bajo la perspectiva de la agencia animal a través de varios objetos artísticos encontrados en el asentamiento de Polizzello (Sicilia occidental), datados entre los ss. VIII-VI a. C. Concretamente, presentamos un conjunto de jarras cerámicas decoradas con bucráneos, así como también representaciones de bovinos y seres híbridos en distintos soportes cerámicos como son vasos de almacenamiento, de consumo y servicio de alimentos. En primer lugar, nos centraremos brevemente en explicar el contexto histórico y social de la isla en la Edad del Hierro, haciendo especial énfasis en sus tradiciones artísticas. Seguidamente, presentaremos el asentamiento de Polizzello y los distintos materiales de estudio. Finalmente, interpretaremos estos objetos bajo el prisma de los estudios animales para explicar la importancia de los bueyes en la participación activa de las dinámicas sociales de los humanos.

PALABRAS CLAVE: Sicilia; Edad del Hierro; Arte antiguo; Bucráneos; Iconografía; Bovinos; Agencia animal; Animales no humanos.

\section{Animal Agency in Iron-Age Sicilian Art (VIII-VI BCE): Interaccion between Bovines and Man}

\begin{abstract}
This paper proposes an analysis of the relationship between bovines and humans through the lens of animal agency, using various artworks recovered from the site of Polizzello (western Sicily) dated between the $8^{\text {th }}$ and the $6^{\text {th }}$ centuries BCE. Specifically, we study a group of table amphorae decorated with bucrania, together with representations of these animals and hybrid beings painted on clay dishware. First, we will explain briefly the historical context and the artistic traditions of the island. Next, we will describe the site of Polizzello and the range of artworks. Finally, we will discuss these objects under the lens of the so-called «animal-studies» to highlight the important role of the bovines in human social dynamics.
\end{abstract}

KEYWORDS: Sicily; Iron Age; Ancient Art; Bucrania; Iconography; Bovines; Animal agency; Nonhuman animals.

Recibido: 28 de febrero de 2019 / Aceptado: 14 de julio de 2019.

\section{Introducción}

La importancia de los animales en la cultura visual del pasado se plasma ya en las primeras representaciones artísticas de nuestra especie. Como han constatado diversos estudios (Sanchidrián, 2018), los animales son los protagonistas principales del arte durante el Paleolítico Superior, tanto en soporte parietal como mueble. Muchas han sido las interpretaciones sobre el significado de dichas imágenes, desde simples decoraciones de las cuevas -asimiladas a las casas de los habitantes prehistóricos-, hasta productos de rituales propiciatorios de caza, pasando por imágenes totémicas o representaciones de códigos de comunicación basados en un sistema binario de opuestos, así como también plasmaciones de estados alterados de consciencia en el marco de rituales de tipo chamánico (Clottes y Lewis Williams, 2010; Rusell, 2012: 13-18). A pesar de la heterogeneidad de las definiciones, un punto en común en todas ellas es su visión marcadamente antropocéntrica, que

Cómo citar este artículo: LÓPEZ-BERTRAN, Mireia y FERRER, Meritxell, «La agencia animal en el arte siciliano de la Edad del Hierro (ss. VIII-VI a. C.): interacciones entre bovinos y humanos", Boletín de Arte-UMA, n. ${ }^{\circ} 40$, Departamento de Historia del Arte, Universidad de Málaga, 2019, pp. 179-193, ISSN: 0211-8483, e-ISSN: 2695-415X, DOI: http://dx.doi.org/10.24310/BoLArte.2019.v0i40.5788 
conlleva la supeditación reiterada de los animales a los humanos. Recientemente, sin embargo, algunas investigaciones han interpretado la preponderancia de los animales en este arte como una de las múltiples maneras de mostrar una cohabitación entre animales y humanos basada en las relaciones complejas que se crean en el marco de las actividades de caza, las cuales van más allá de la simple asociación entre humano-cazador/animal-presa (Gittins, 2013).

En ámbito Neolítico uno de los grandes temas de estudio es el origen de la domesticación de la flora y la fauna. En este contexto se asienta de manera más clara la mirada antropocéntrica sobre los animales, ya que se asume que los humanos entienden los animales como materia prima para controlar, domesticar, sacrificar y consumir en una clara relación de superioridad. A pesar de ello, algunos trabajos defienden que la domesticación no se debe entender como un ejemplo de control de los humanos sobre los animales, sino que a través de este proceso se establece una relación de reciprocidad, simbiosis y relaciones cambiantes entre animales y humanos que afectaría a todos sus participantes -tanto animales como humanos-, creando así un proceso de codomesticación (Boyd, 2017: 305-304).

A nivel artístico, cabe señalar que durante el Neolítico se enfatizan las imágenes de humanos y disminuyen la de los animales. Pese a este cambio respecto al periodo anterior, es interesante observar cómo los animales representados no son los domesticados sino los salvajes que, precisamente, se representan en escenas de interacción con los humanos, especialmente a través de imágenes de caza (Boriç et al., 2013: 56). Tradicionalmente, estas imágenes evidenciarían cómo los humanos se habrían situado por encima del mundo animal, a la vez que también expresarían un deseo de dominación sobre los animales salvajes quienes, al no encontrarse bajo dominio humano, serían considerados peligrosos. De esta manera, se crea una división entre animales-naturaleza, hombres-cultura por la que los primeros son situados en un nivel inferior respecto a los humanos (Boyd, 2017: 206). En definitiva, los análisis de las imágenes de animales en la Prehistoria han sido habitualmente interpretados desde una perspectiva simbólica en la que los animales se entienden como metáforas para los grupos humanos con el fin de plasmar visualmente su dominación sobre la naturaleza, así como también el valor mágico-medicinal de algunos animales, preferencias o tabús alimenticios o construccio- nes de género, edad o estatus de las personas humanas. Con ello, los animales -tanto representados como reales- se convierten en meros instrumentos pasivos de los humanos, negando a estos cualquier posibilidad de participar activamente en las interacciones sociales con los grupos humanos (Hill, 2011; 2013).

Pese a la tradicional hegemonía de esta perspectiva instrumentalista, en los últimos años esta visión está siendo cuestionada desde las Humanidades a partir de los llamados "estudios animales", enmarcados en las tradiciones post-humanistas que rechazan las dicotomías cartesianas tales como cultura/naturaleza, humano/animal o animado/ inanimado (Thomas, 2007; Harrison-Buck y Hendon, 2018: 3-6). Concretamente, estas teorías aplicadas al estudio de las sociedades del pasado y a su cultura visual están influenciadas por las propuestas de B. Latour, N. Bird-David, P. Descola o E. Viveiros de Castro (Boyd, 2017: 302) y se insertan en perspectivas arqueológicas de corte postmoderno en las que las relaciones animales-humanos se presentan como interacciones bidireccionales y de reciprocidad que, aunque asimétricas, ponen a un mismo nivel interpretativo a los animales. En este sentido, los animales -lejos de ser un mero instrumento pasivo- influencian a los humanos tanto desde el punto de vista biológico como emocional, siendo el arte una de las múltiples maneras de construir este vínculo.

Los «estudios animales» emergen hacia finales del siglo XX en el campo de la antropología socio-cultural y reconocen la omnipresencia de los animales en las sociedades a nivel práctico, metafórico, material y corporal (Boyd, 2017: 302; Cederholm et al., 2014; Ritvo, 2007). En el caso de los estudios que se ocupan del pasado, este enfoque también se conoce con el término de «zooarqueología social» y se caracteriza por poner de manifiesto la agencia de los animales, es decir, su capacidad de acción y de interactuar. Así, dotar a los animales de agencia supone definirlos con características que en la sociedad moderna occidental se vinculan únicamente a los humanos -como, por ejemplo, la personalidad-, lo que conlleva la necesidad de distinguir entre personas-animales y personas-humanas. En este sentido, los animales-persona se relacionan entre ellos y con los humanos en términos sociales y son sujetos capaces de comunicar y tomar decisiones que afectan a los humanos (Hill, 2013: 121). Esta visión forma parte de las metodologías relacionales de la personalidad que enfatizan el entendimiento de las 
personas más allá de una entidad singular e indivisible puesto que las personas -humanas y animales- construyen su identidad mediante conexiones e intercambios, no solo con otras personas, sino también con objetos, espíritus o plantas. Por lo tanto, la definición relacional de las personas enfatiza su vertiente dividual, interdependiente, modular y observa cómo estas están formadas por las substancias y acciones de otros, tanto humanos como no-humanos (Fowler, 2004 y 2008; Robb y Harris, 2013). Los diversos casos de estudio que aplican estas ideas dan cuenta de la complejidad del tema puesto que, dependiendo de cada sociedad, no todos los animales de una especie tienen la potencialidad de convertirse en personas ni, en el caso de serlo, es necesario que lo tengan de forma continua a lo largo de todos sus ciclos vitales (Hill, 2018). Igualmente, cabe decir que las personas-animales también pueden ser consumidas por las personas y, de hecho, la ingesta puede formar parte de la relación entre los dos tipos de personas (Russell, 2012: 4).

Las evidencias de cultura material que dan cuenta de la existencia de animales-personas en el pasado o en culturas preindustriales actuales son varias como, por ejemplo, la preeminencia de restos osteológicos de determinadas especies, los depósitos ritualizados en los que aparecen restos de animales que han participado en ritos o festividades o los animales que han sido enterrados con la liturgia fúnebre propia a priori de los humanos. Pese a esta variedad de manifestaciones, el campo que nos ofrece información privilegiada respecto a la existencia de estos seres son las fuentes artísticas y arquitectónicas. Así, se han documentado partes de animales, sobre todo dientes, que participan en la creación de piezas de arte corporal, como collares o elementos de vestimenta como gorros (Boriç et al. , 2013: 36-37). Igualmente, pinturas murales con representaciones de animales, como los frescos de los palacios minoicos (Shapland, 2010) o los relieves escultóricos con motivos animales de Göbleki Teppe (Turquía) (Boriç, 2013) han sido interpretados bajo estas premisas. En esta línea, la manipulación de determinadas partes de animales, cabezas y cornamentas principalmente, para ser insertados en muros mediante enyesados en los muros de casas de Çatal Hüyük (Turquía) (Hodder y Meskell, 2010) se ha interpretado como estrategia visual de construir animales-personas.

De acuerdo con estas premisas, en este trabajo presentamos un caso de estudio específico basado en la repre- sentación de bueyes y seres híbridos (bóvidos-humanos) en las cerámicas indígenas de Sicilia occidental durante la primera Edad del Hierro (ss. IX-VIII a. C.). Concretamente, nos centraremos en las obras procedentes del asentamiento de Polizzello, al ser este el lugar donde más materiales de este tipo se han documentado. Para reforzar nuestros argumentos en algunos casos también utilizaremos materiales procedentes de otros centros sicilianos contemporáneos. La interacción bueyes-humanos aparece plasmada con la inserción de bucráneos en jarras cerámicas, así como también en la representación de bovinos y seres híbridos en distintos soportes cerámicos como son vasos de almacenamiento, de consumo y servicio de alimentos. En primer lugar, nos centraremos brevemente en explicar el contexto histórico y social de la isla en la Edad del Hierro, haciendo especial énfasis en sus tradiciones artísticas. Seguidamente, presentaremos el asentamiento de Polizzello y los distintos materiales de estudio. Finalmente, interpretaremos estos objetos bajo el prisma de los estudios animales para explicar la importancia de los bueyes para las poblaciones locales sicilianas de la Edad del Hierro.

\section{Sicilia y su tradición artística durante la Edad del Hierro}

El conocimiento de Sicilia durante el I Milenio a. C. está claramente sesgado por las informaciones relatadas por los autores clásicos, como Tucídides y Diodoro de Sicilia, quienes agruparon las comunidades locales dispersas a lo largo de toda la isla bajo diferentes etnónimos: sículos, sicanos y elimios. Independientemente del momento en el que se formaron estas etnicidades, a partir del Bronce Final (c. 1.200-900 a. C.) y, sobre todo, durante toda la Edad del Hierro (c. 900650 a. C.) las poblaciones locales se asentaron en las crestas de ciertas colinas erigidas a lo largo de todo el territorio siciliano (Leighton, 1999: 187). Ejemplo de ello son Segesta, Entella, Morgantina, Colle Madore, Polizzello o Monte Polizzo [1]. La gran visibilidad sobre el paisaje de estos asentamientos se complementaba con su situación en espacios de fácil acceso a la red fluvial siciliana, lo que dotaba a estos centros no solo de una cómoda comunicación entre ellos, sino también con las distintas colonias fenicias y griegas que, a partir de mediados del siglo VIII a. C., se 


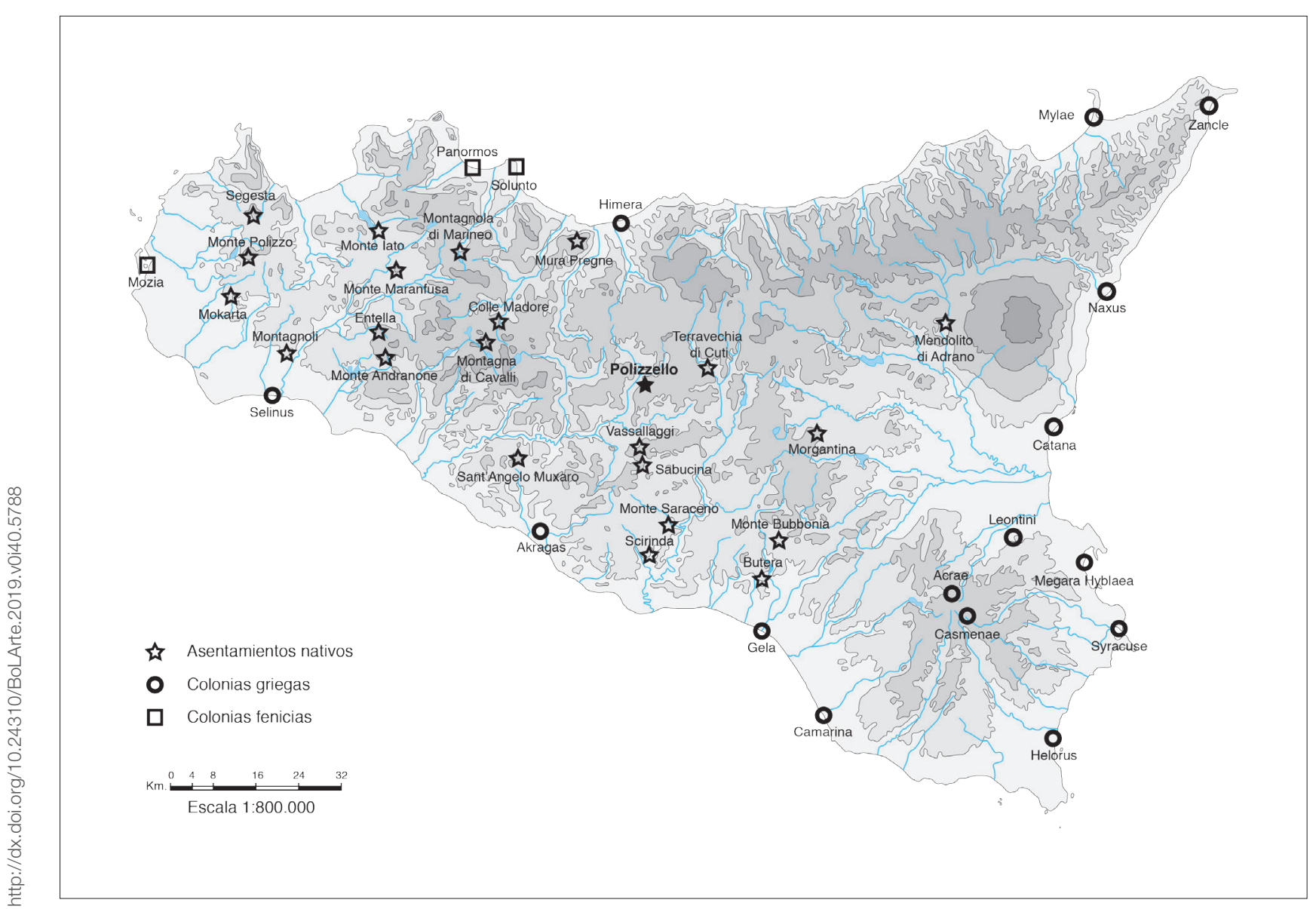

1. Mapa de Sicilia señalando los principales asentamientos indígenas de la edad del Hierro y las colonias griegas y fenicias asentadas en la isla

asentaron a lo largo de toda la costa de la isla. Esta estratégica posición en el paisaje también permitía a las comunidades locales acceder cómodamente tanto a fértiles valles agrícolas como a otras zonas destinadas principalmente al pastoreo. De hecho, la agricultura y la ganadería eran los dos principales recursos económicos de estas poblaciones, los cuales serían complementados por distintas actividades desarrolladas tanto en los frondosos bosques circundantes -principalmente la caza-, como en los mismos asentamientos, principalmente la producción cerámica, metalúrgica o textil (Ferrer, 2010: 210).

La continuidad documentada en el patrón de asentamiento de las comunidades locales sicilianas desde finales del II Milenio hasta mediados del I Milenio a. C. también se observa a nivel artístico. Pese al escaso volumen de representaciones identificadas en el repertorio cerámico de am- bos milenios, cabe señalar que a partir de mediados del II Milenio a. C. se observa la emergencia de una tradición figurativa propia, principalmente de carácter zoomórfico (Cultraro y Crispino, 2015: 41). Estas primeras representaciones se encuentran en algunos vasos relativos a la cultura Thapsos (s. XIV-XIII a. C.) $)^{2}$, la mayoría de ellos documentados tanto en contextos funerarios como domésticos (Cultraro y Crispino, 2015: 42). Entre los motivos representados destacan principalmente las aves -animales que aparecen por primera vez en el repertorio figurativo siciliano- tanto de manera individual como colectiva y decorando una amplia diversidad de formas vasculares como son botellas, copas o cuencos (Cultraro y Crispino, 2015: 42-43). Junto a estas representaciones aviarias destaca también la figuración de algún animal cuadrúpedo, posiblemente aludiendo a animales equinos -caballos o asnos-, así como también un bucráneo 
sobre el cual se encuentra una media luna (Cultraro y Crispino, 2015: 43). Dentro de este imaginario dominado absolutamente por los animales, destaca la casi completa ausencia de figuraciones antropomórficas, documentándose hasta el momento solo una en una copa-quemaperfumes procedente de la Tumba 6 de Thapsos (Cultraro y Crispino, 2015: 43).

La tradición figurativa de animales presente en algunos de los vasos de la cultura Thapsos parece desaparecer en la fase siguiente, la denominada cultura de Pantalica (1.250-1.150 a. C.), donde por el momento no se han documentado representaciones zoomórficas o antropomórficas (Cultraro y Crispino, 2015: 44). No obstante, se retoma con ciertas diferencias poco tiempo después, registrándose los primeros ejemplos en el siglo XI a. C. De hecho, es en la fase final de esta tradición en la que se insieren los ejemplos de Polizzello posteriormente analizados.

A diferencia del periodo anterior ampliamente dominado por la representación aviaria, en este momento adquieren gran relevancia los bóvidos, animales que aparecen representados tanto a través de la plástica adherida a algunos vasos a modo de asa como decorando algunos recipientes cerámicos ya sea por medio de pintura o de incisión La relevancia de este animal, asimismo, se observa por la documentación a partir del siglo IX-VIII a. C. de algunas representaciones en miniatura de este animal (Cultraro y Crispino, 2015: 44-45).

En relación a la importancia de estos animales a nivel iconográfico cabe señalar que esta no es única ni exclusiva de Sicilia, sino que se enmarca en un contexto Mediterráneo que abarca desde el Neolítico hasta la cultura greco-romana. El valor ideológico de los bóvidos, especialmente de los toros, ha sido vinculado a menudo con divinidades masculinas, a las cuales precisamente, se les ofrecen sacrificios de estos animales, sirva como ejemplo el pasaje de la llíada (VIII: 228, IX: 434). Se trata de divinidades creadoras y de tipo fertilístico cuyas representaciones aparecen en varios soportes y en contextos religiosos (Azara, 2002).

\section{Polizzello y los bovinos}

En la Sicilia del Hierro Antiguo la complejidad de las relaciones entre animales y personas tiene como ejemplo privilegiado el caso de los bovinos, especialmente bueyes si atendemos a los taxones recuperados en los distintos asentamientos. En efecto, la relevancia de estos animales en la economía siciliana es testimoniada a través del considerable registro de sus restos óseos tanto en contextos domésticos (Monte Polizzo: Mühlenbock, 2008; Monte Maranfusa: Di Rosa, 2003) como rituales, bien en las acrópolis (Monte Polizzo: Hnatiuk, 2003; Colle Madore: Di Rosa, 1999; Polizzello: Palermo et al. , 2009; Sabucina: Guzzone, 2009: 95) o los espacios funerarios (Morgantina: Leighton 1993; PolizzeIlo: De Miro, 1988; Di Salvo et al., 2012).

Esta reiterada presencia de los bueyes en los contextos sicilianos del Hierro sugiere que el ganado vacuno no solo adquirió una gran relevancia en las economías de estas gentes, sino que también compartía las rutinas, las temporalidades y los espacios cotidianos con los humanos. De hecho, si bien los bovinos podían participar activamente en distintas prácticas agrícolas como la labranza, también se alojaban en el mismo asentamiento. La importancia ostentada por estos animales en el día a día de estas grupos se plasma, asimismo, a nivel artístico al documentarse distintos objetos cerámicos que o bien presentan apliques plásticos de cornamentas de bueyes, decoraciones pintadas con seres híbridos, o figurillas de arcilla de vacunos colocadas en el interior de vasos cerámicos. Este tipo de vasos en los que se hace patente la exaltación del bovino se documenta con cierta contundencia en Polizzello, donde han sido documentados tanto en contextos funerarios como en depósitos relativos a la acrópolis.

El asentamiento de Polizzello se localiza en una montaña homónima situada en la parte alta del valle del río Platani (Mussomeli, Caltanissetta), en Sicilia central, el cual fue habitado interrumpidamente desde el s. X a. C. hasta el s. V a. C. (Palermo et al., 2009) [2]. De acuerdo con el patrón tripartito de organización espacial que presentan los asentamientos sicilianos contemporáneos, en la parte más alta de la colina se encuentra un complejo de carácter ritual -la denominada acrópolis- que se caracteriza por una continua sucesión de estructuras rectangulares y circulares en cuyo interior, así como también en los espacios abiertos colindantes, tuvieron lugar distintas prácticas de carácter cultual desde finales del siglo X hasta inicios del siglo V a. C. (Guzzone et al., 2009; Palermo et al., 2009).

En un segundo nivel, en el área inminentemente inferior a esta plataforma, se ubicaban distintos contextos do- 


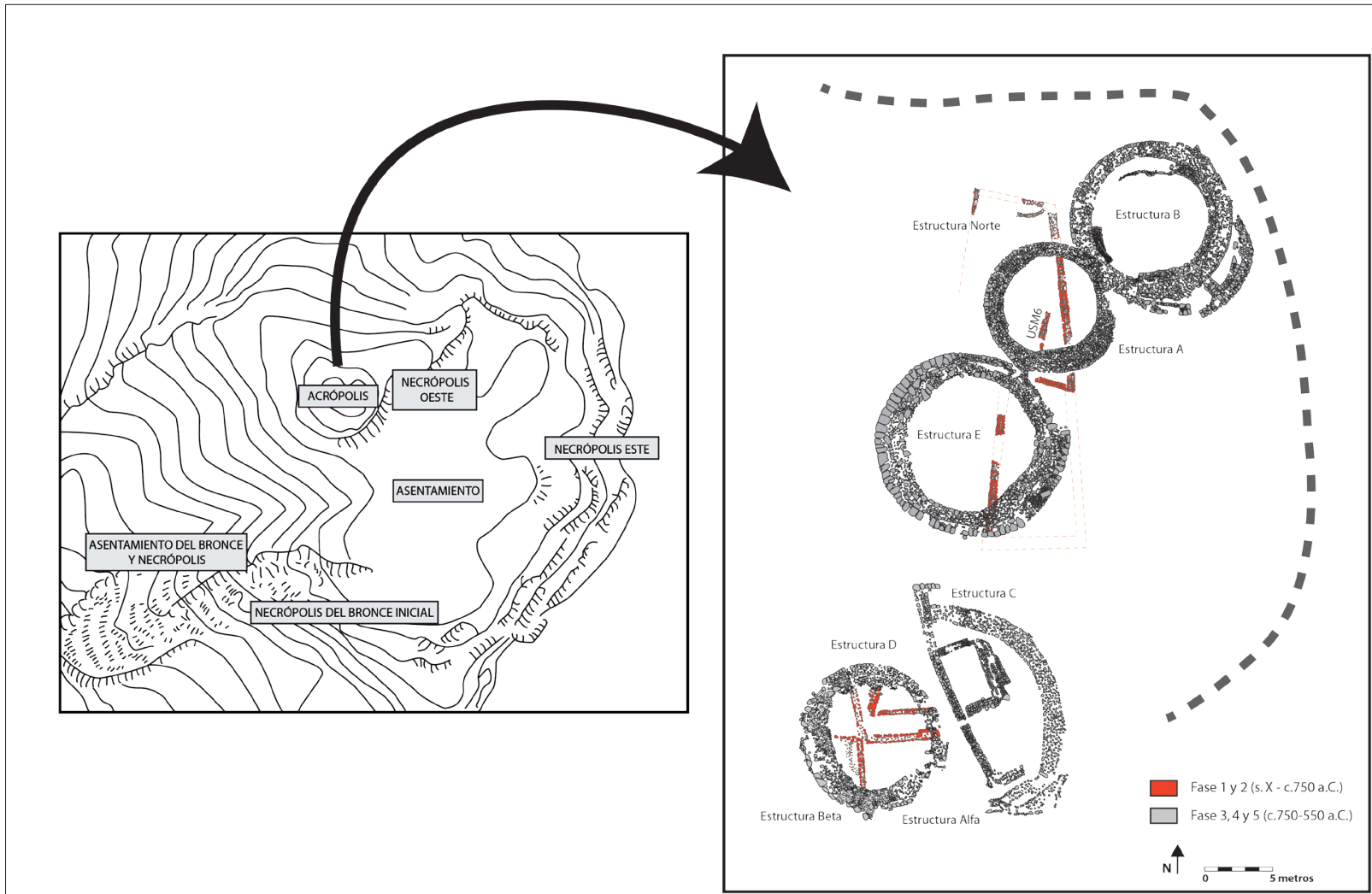

2. Organización espacial del asentamiento de Montagna di Polizzello (a partir de Guzzone et al. 2009 fig. 1) y estructuras de su acrópolis (Palermo et al. 2009: fig. 1)

mésticos de acuerdo a un sistema de terrazas artificiales. Finalmente, en la parte media de la pendiente oriental y occidental de esta montaña se encuentran dos necrópolis. Ambas necrópolis están constituidas por numerosas cámaras excavadas en la roca, de planta tanto circular como rectangular, a las que se accedía por medio de un pequeño dromos. Estos espacios funerarios fueron reutilizados durante varias generaciones, documentándose por ejemplo en el interior de la tumba 25 hasta cinco estratos de deposición (De Miro, 1988; Fiorentini, 1999).

Cerámicas decoradas de la necrópolis

Dentro del corpus cerámico documentado en las tumbas de Polizzello destacan algunos recipientes destinados tanto al servicio de bebidas -ánforas de mesa, enocoes- como al consumo de productos líquidos y semi-líquidos -boles- con representación de bovinos.

En la necrópolis Este se identificaron diversas tumbas talladas en la roca a las cuales se accedía por dromoi, en los que, en algunos casos, también se depositaron cuerpos de adultos y niños. Algunos de estos enterramientos tenían un pequeño espacio a cielo abierto donde se han recuperado materiales que seguramente serían utilizados durante el sepelio, así como también en visitas posteriores a los enterramientos (De Miro, 1988: 35; Fiorentini, 1999: 197). Precisamente en estos espacios adyacentes a las tumbas se han documentado distintos vasos cerámicos con representaciones plásticas de bovinos que se caracterizan por compartir el mismo programa iconográfico. Ejemplo de ello es la deposición 7 del espacio exterior asociado a la tumba 5 y $5 \mathrm{~A}$, donde se documentaron dos ánforas y dos boles fechadas en el s. VII a. C. [3]. 


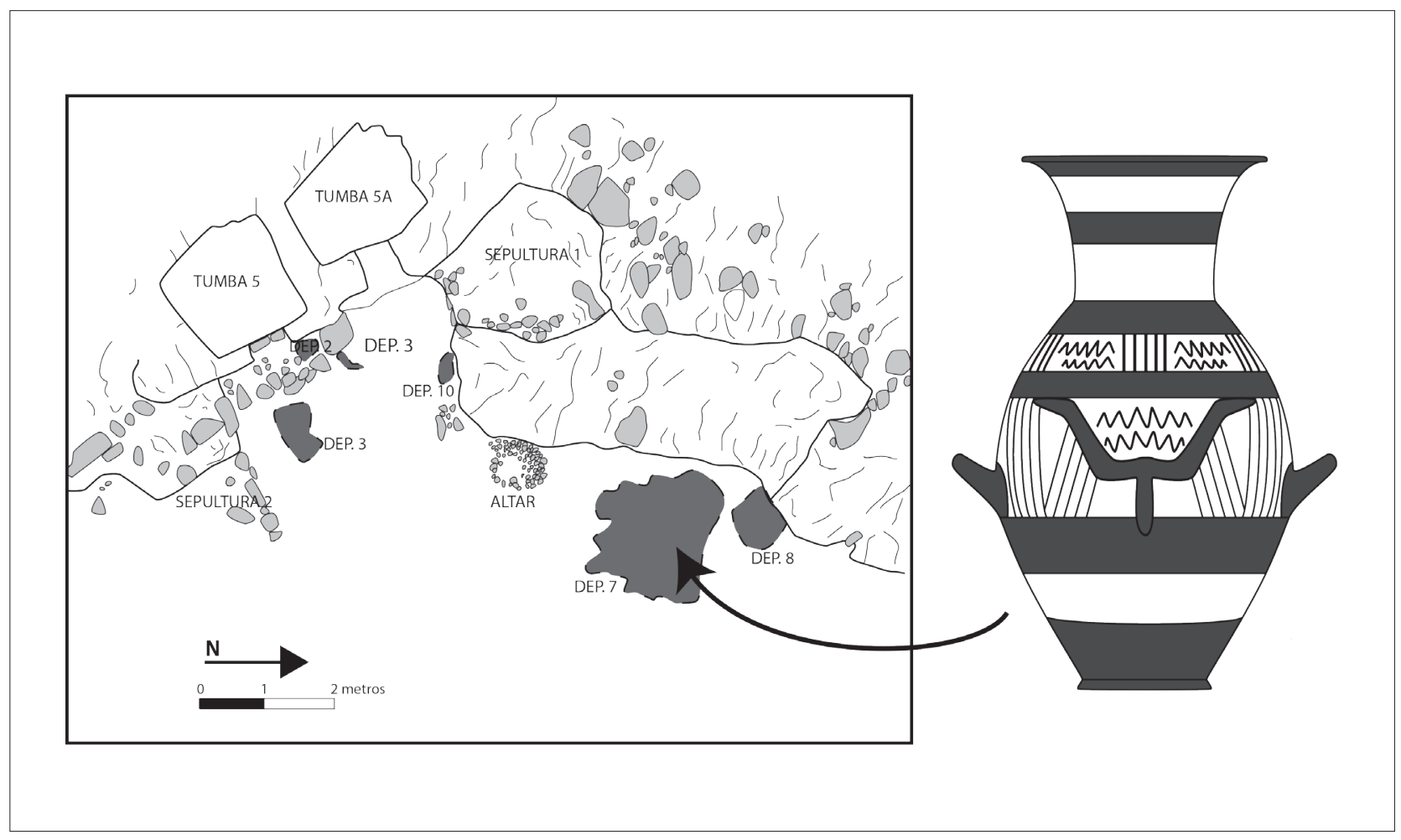

3. Sector A de la Necrópolis Este de Montagna di Polizzello (a partir de De Miro 1988: fig. 8) y ánfora de mesa con representación de bovino documentada en la deposición 7 (a partir de Trombi 2003: tav. III, cat. 20)

La primera de estas ánforas de mesa presenta una longitud de $27,5 \mathrm{~cm}$ y muestra el cuerpo pintado con tres bandas de color rojizo. Las bandas situadas entre las ansas sirven para enmarcar un patrón decorativo doble en un lado de la jarra. Por un lado, se pintan una serie de motivos de líneas oblicuas a modo de retícula. Por otro lado, la retícula queda dividida en dos gracias al aplique de arcilla que representa un rostro estilizado de un buey, con la cornamenta muy exagerada (Panvini, 2003: 212). El segundo ejemplar presenta una morfología muy similar respecto al anterior, aunque su altura es ligeramente superior (29,5 cm). Su esquema compositivo es parejo al ánfora de mesa previa, mostrando entre las franjas inferiores y media un conjunto de trazos verticales y oblicuos que forman un complejo sistema decorativo. A estos motivos se añade un prótome plástico de bovino que en el espacio intermedio de las cornamentas presenta un motivo en zig-zag (Panvini, 2003: 212). De este mismo contexto provienen dos boles carenados dispuestos sobre un largo pie modelados a torno, en cuyo interior se coloca una pieza hecha a mano que recuerda a unas cornamentas estilizadas (Panvini, 2003).

En el interior de la tumba 25, usada como panteón durante varias generaciones a juzgar por el registro de cinco estratos de deposición, se ha documentado otra ánfora de mesa con figuración bovina. En este caso, este ánfora se documenta en el cuarto nivel de su estratigrafía, fechado en el s. VII a. C. [4]. A diferencia de las ánforas anteriores, esta jarra presenta el cuerpo decorado con incisiones de tipo triangular que enmarcan las cornamentas plásticas, mientras que el prótome está decorado con tres circunferencias inscritas mediante tres círculos concéntricos colocados debajo de cada cuerno y en el arranque de ambos (Trombi, 2003: 702).

Junto a estos ejemplos cabe señalar otro vaso sin contexto de hallazgo que presenta el mismo tipo iconográfico. Esta ánfora presenta decoraciones incisas y bucráneos plásticos a ambos lados. Sin embargo, a diferencia de las otras, los 4 cuernos dividen la superficie en cuatro registros 


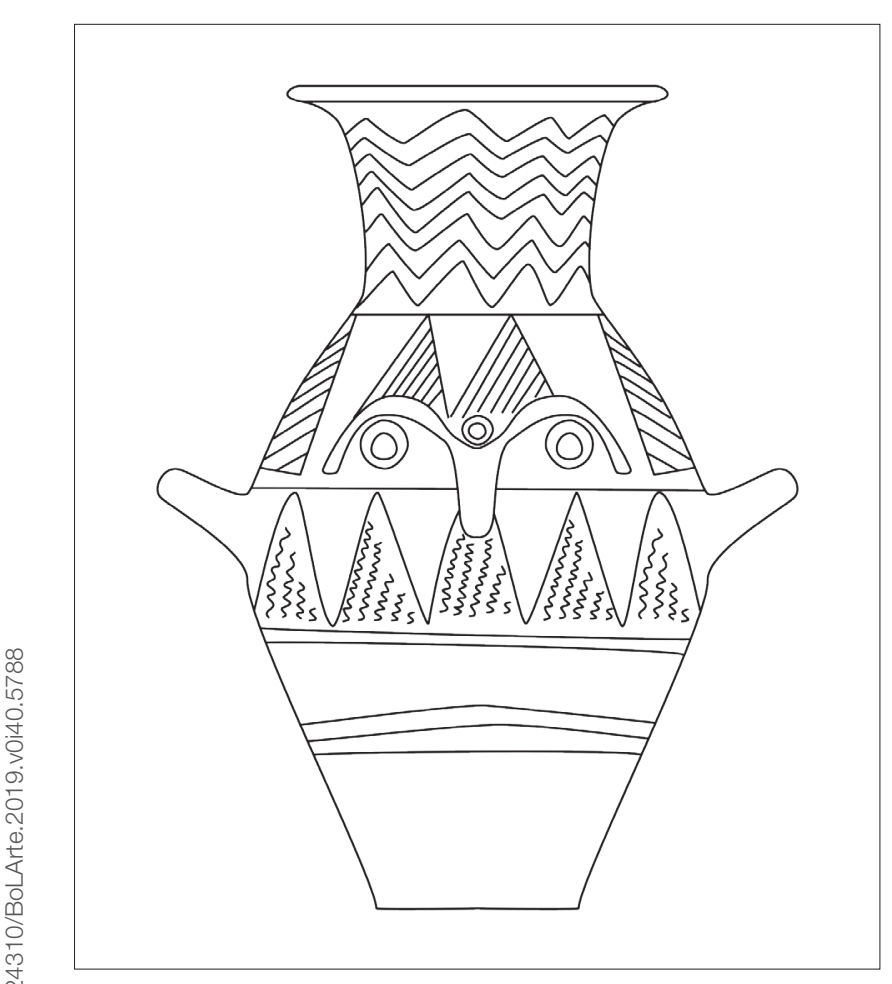

4. Ánfora de mesa con representación plástica de un bucráneo procedente de la tumba 25 de la necrópolis de Montagna di Polizzello (a partir de Trombi 2003: tav. II, cat. 19)

o metopas con un rico programa iconográfico inciso [5]. En el primero de ellos aparece representado un hombre montado a caballo que tiene la cabeza decorada con una gran cornamenta y un amplio faldón; seguidamente se encuentra un bovino con rasgos esquemáticos y con unos cuernos desproporcionados en forma de media luna; en el tercer registro se inserta un gran círculo decorado por una franja circular decorada con un zigzag continuo de la que parten tres triángulos convergentes con su interior adornado con pequeñas incisiones a modo de puntos. Finalmente, el último elemento ornamental son dos pájaros de manufactura esquemática (Vassallo, 1999: 214; Cultraro, 2012: 390).

Pese a la peculiaridad de estas ánforas de mesa con bucráneos, cabe señalar que este tipo de vasos no son exclusivos de Polizzello, sino que se enmarcan en una tradición artística que abarca toda la parte occidental de la isla hasta el siglo VI a. C. (Trombi, 2003: 695-696). De hecho, piezas similares han sido documentadas en Naro (Leighton, 1999; Trombi, 2003), Nicosia (Castellana, 1994) o Entella (Falso-

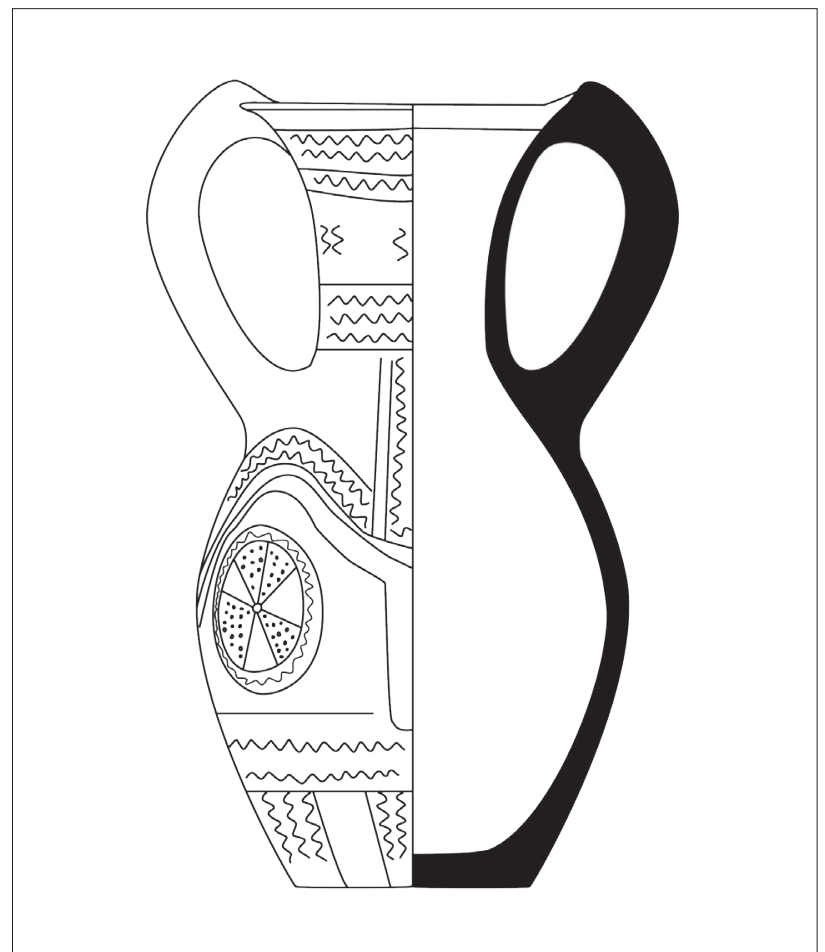

5. Ánfora de mesa hallada en la zona de Mussolemi-Polizzello con decoraciones incisas y bucráneos plásticos a ambos lados (a partir de Trombi 2003: tav. II, cat. 18)

ne, 1980; Falsone et al., 1993; Leighton, 1999) [6], aunque, desafortunadamente, la gran mayoría de ellos son hallazgos esporádicos y no tienen un contexto de hallazgo claro que pueda arrojar más luz a su función y significado.

Figurillas de bovinos y seres híbridos de la acrópolis

Junto con las áreas funerarias, la acrópolis representa otro espacio ritual dentro del asentamiento de Polizzello (De Miro, 1988; Guzzone et al., 2009; Palermo et al., 2009). En este ámbito destinado a la celebración periódica de ceremonias rituales de carácter comunal también se han documentado distintos objetos artísticos asociados con los bovinos. No obstante, a diferencia de aquellos documentados en la necrópolis, en las acrópolis sobresalen las representaciones de seres híbridos.

Entre los distintos vasos documentados en este espacio ritual sobresale el denominado enocoe del «pulpo» [7]. 


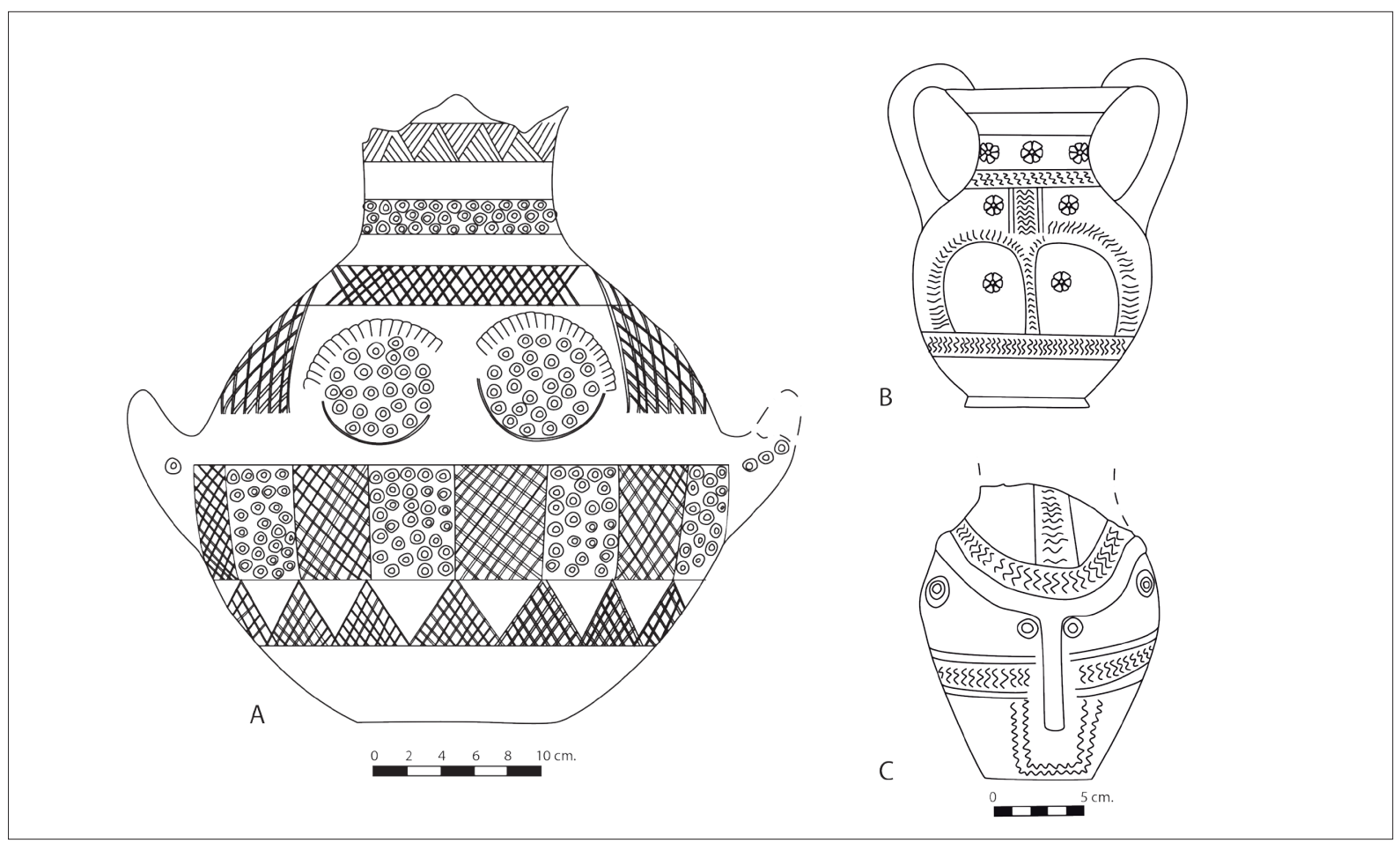

6. Ánforas de mesa con representación bucránea halladas en: A) Entella (a partir de Falsone, 1980: fig. 4); B) área de Polizzello (a partir de Leighton, 1999: fig. 145); C) Naro (a partir de Leighton, 1999: fig. 145)

Este recipiente responde a una jarra para servir líquidos de una sola asa cuyo cuerpo aparece ornamentado con tres motivos distintos, uno frontal y dos laterales realizados con pintura negra. El contexto exacto de hallazgo de este vaso se desconoce. No obstante, a partir de la morfología se ha fechado en el s. VII a. C., siendo coetáneo a los materiales anteriormente mencionados de la necrópolis.

A nivel de los motivos decorativos, en la parte frontal se reconoce un pulpo estilizado rodeado por franjas semicirculares que algunos autores han interpretado como un laberinto (Cultraro, 2012). En ambos lados aparecen representados sendos seres híbridos formados por un personaje antropomorfo con las rodillas flexionadas en el que sobresale el falo erecto y va tocado con cornamentas. Asimismo, su posición de perfil permite diferenciar la nariz, la boca y una larga barba. Estas figuras han sido interpretadas como guerreros, definiéndose así el tocado como un casco y el motivo circular que rodea el torso de la figura con un escudo (Cultraro, 2012: 390).
La iconografía guerrera también aparece en una figurilla de arcilla modelada a mano con una altura de 10,5 cm encontrada en el edificio B. A pesar de que ha perdido gran parte de las extremidades superiores e inferiores, el motivo iconográfico se asemeja al caso anterior. En ella se aprecia la figura de una persona con pene erecto y tocado con un casco con penacho del que arrancan dos pequeñas protuberancias en la base. La nariz tiene una forma apuntada triangular y el mentón también aparece resaltado. Además, toda la pieza presenta restos de pintura, evidenciándose principalmente en el casco, los ojos, el pene y la parte trasera. Junto a esta figurilla también se documentó un disco con restos de pintura que posiblemente representaba un escudo asociado a ella (Guzzone, 2006: 244, 245).

En este edificio B también se halló un bol cuyo interior presenta una decoración pintada y en el centro dos figuras de arcilla modeladas a mano que representan una vaca, con cabeza, cuernos y ojos realizados con incisiones, y un ternero de forma muy esquemática que parece estar mamando. 


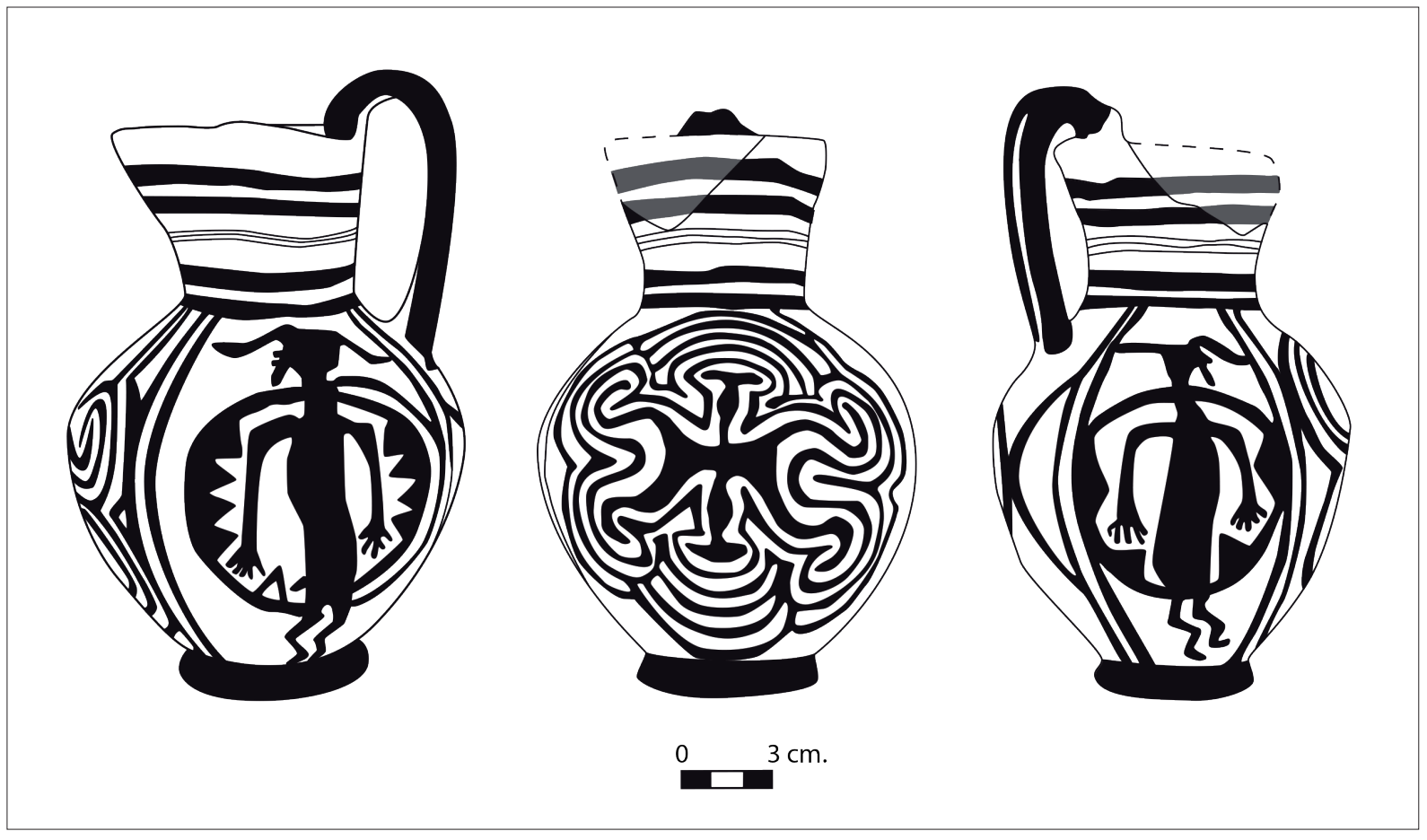

7. Enocoe «del pulpo» (a partir de Leighton, 1999: fig. 148)

Ambas representaciones también presentan restos de dos bandas gruesas de pintura que parecen resaltar las grupas (Guzzone, 2006: 267). Finalmente, cabe señalar el hallazgo en la misma estructura de un exvoto realizado en hueso en forma de pata de bovino en la que se representa con mucho esmero la pezuña. El objeto seguramente formaba parte de un objeto más completo, tal y como sugieren las señales de ruptura evidenciadas en la parte superior (Guzzone, 2006: 270; De Miro, 1988: 33, fig. 3B.).

\section{Identidades fluidas entre bovinos y humanos a través de las imágenes}

Las obras plásticas que acabamos de comentar han sido analizadas como ejemplos artísticos para mostrar de forma visual la importancia de una economía de subsistencia basada en la combinación del pastoreo y las prácticas agrícolas en las que también participarían estos animales (Cultraro y Crispino, 2015: 44). Como ya hemos comentado, los análisis zooarqueológicos de diferentes comunidades sicilianas muestran un alto porcentajes de restos de Bos taurus tanto en espacios residenciales como en las acrópolis (Ferrer, 2013), por lo que consideramos que algunos de los animales representados serian bueyes, es decir, bovinos que han sido castrados con el fin de ser animales más pacíficos y grandes para participar en las actividades agrícolas. No obstante, dentro de estas representaciones, sobre todo aquellas relativas a seres híbridos, posiblemente también se hacía referencia a toros, bovinos sin castrar, que tradicionalmente en las sociedades antiguas mediterráneas se han asociado con la riqueza y la fuerza, representando en muchos casos masculinidades fundamentadas en la guerra y el heroísmo (Cultraro, 2012: 393).

Junto a estas interpretaciones fundamentadas principalmente en enfatizar el valor ideológico de los bovinos desde una perspectiva antropocéntrica, estos objetos también son perceptibles de ser analizados bajo la mirada de la interacción entre animales y humanos desde una perspectiva relacional. En base a esta metodología, estas figuraciones dejan de ser analizadas como simples motivos artísticos pasivos y se ponen de manifiesto distintos modos en los que 
los animales representados en los diferentes soportes participan activamente en actividades rituales y de prestigio. En la obtención de este objetivo es fundamental considerar la materialidad de las imágenes; es decir, analizar su vertiente práctica y/o funcional ya que las imágenes ayudan a constituir relaciones sociales (Gell, 1998; Knappet, 2005; DeMarrais y Robb, 2013). Igualmente, es importante considerar una metodología destinada a advertir el grado de fluidez en las relaciones entre lo humano y lo animal que pasa por el análisis de tres categorías distintas de relación: la asociación o yuxtaposición deliberada de humanos y animales, la sustitución dada cuando los cuerpos de animales y humanos son sustituibles y, finalmente, la transformación en la que destaca, ante todo, el proceso y no el resultado. Este último tipo de relación es el mundo de los seres híbridos, de los cuerpos animalizados o los animales humanizados (Miracle y Boriç, 2008). En los siguientes apartados analizaremos el repertorio visual de los bovinos bajo dichas premisas.

\section{Bucráneos: más allá de decoraciones}

De acuerdo con las premisas anteriormente mencionadas, los bucráneos plásticos en las ánforas de mesa no serían únicamente simples decoraciones de los vasos, sino que serían una estrategia visual para construir una relación activa entre los bovinos y los humanos a partir del líquido que contendrían estos recipientes. En este sentido, algunos investigadores han resaltado la significación de la arcilla como material de soporte ya que su plasticidad permite enfatizar la materialidad de lo representado y su habilidad de conseguir diferentes formas (Borić et al., 2013: 50; Weismantel y Meskell, 2014: 236).

El hecho que los bucráneos se coloquen en jarras y en boles no sería casual, ya que ambos son contenedores de productos que se consumirían en los ritos asociados a la esfera funeraria. Además, el significado del bucráneo, cráneo de un bovino después de un sacrificio, tiene sentido en estos contextos funerarios pues pueden aludir a los banquetes fúnebres que conmemoran a los difuntos. Aunque desconocemos el contenido de las jarras, es posible que su ingesta por parte de algunos de los participantes en los rituales funerarios - vivos y/o muertos- ayudase a la creación de identidades fluidas entre humanos y bóvidos. Esta sería una práctica que dotaría de personalidad tanto a los humanos como a los animales. Por lo tanto, los líquidos almacenados en estas jarras distinguidas tendrían rasgos característicos de los bovinos que serían incorporados por los humanos mediante su ingesta. De este modo, los bucráneos dejan de ser meros elementos decorativos y se convierten en un tipo iconográfico que dota de agencia a los bovinos, a la vez que se erigen en elementos transformadores de las identidades de las personas animales y de las personas humanas. De la misma manera, los boles con representaciones de cornamentas también pueden materializar el consumo de productos que contienen características propias de los bovinos, así como también la plasmación visual del consumo de productos derivados de estos animales, como son la leche o los guisos de carne.

En base a esto, para toda aquella gente que utilizaba estas jarras o los boles destacados con imágenes de bóvidos, los productos almacenados no eran meros instrumentos transformadores, ya que el hecho de consumir empleando estos objetos distinguidos sería una manera de incorporar -entendido este en su sentido literal de «introducir en el cuerpo»- la persona-animal del buey o vaca. Esta interrelación se puede leer en términos de asociación y sería una característica deseada durante los rituales llevados a cabo en las áreas externas de las tumbas, donde justamente estos vasos han sido localizados. Asimismo, cabe señalar que implantar elementos propios de estos animales en los humanos podría haber sido una manera de establecer vínculos con los ancestros. De hecho, la presencia de estos animales no solo se constata en el repertorio visual, sino también en los restos zooarqueológicos ya que algunas tumbas también contienen restos de Bos taurus en altos porcentajes (Di Salvo et al., 2012: 995).

\section{Bovinos y masculinidades}

La asociación entre bovinos y humanos documentada en ámbito funerario parece ser exclusiva de determinados grupos de participantes, principalmente bueyes y hombres. En relación a ello destaca el hecho que la tumba 1 de Polizzello, donde fueron enterrados únicamente adultos, también destaca por ser la que presenta un mayor volumen de bóvidos, contrastando enormemente con la tumba 2 en la que se do- 


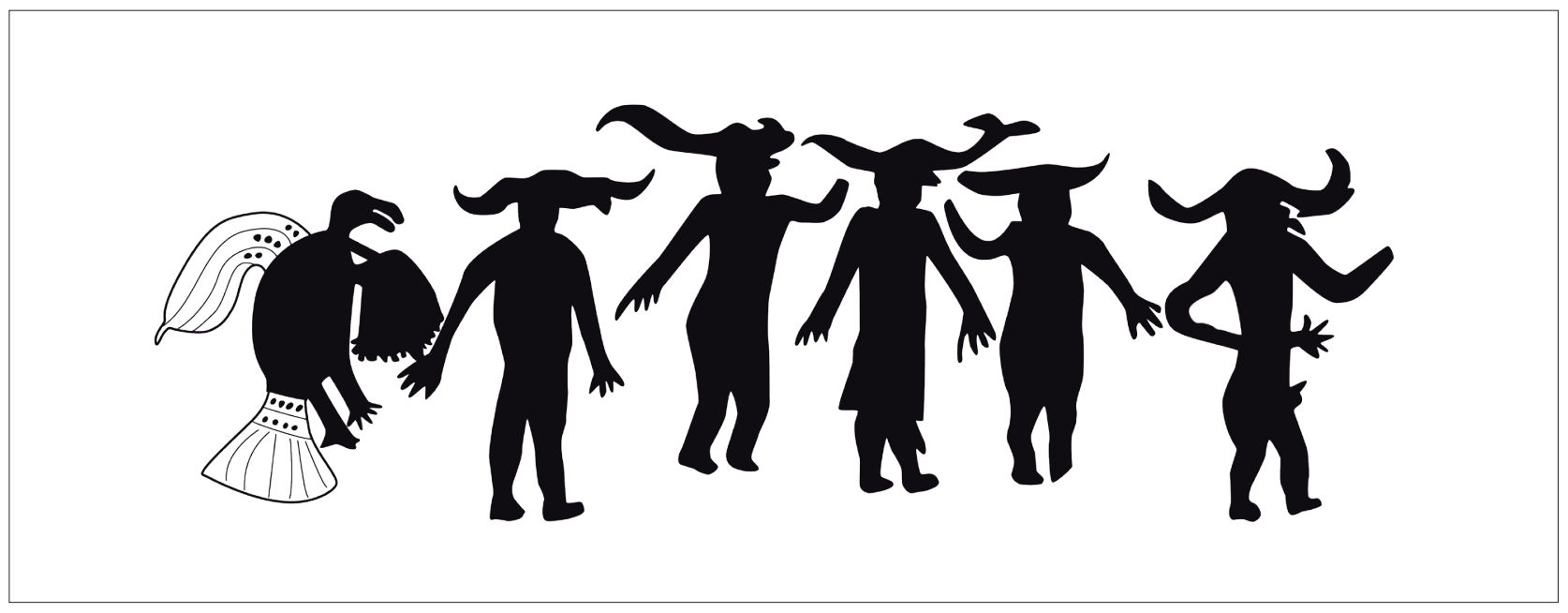

8. Representación decorativa en crátera de contexto desconocido (a partir de Vassallo, 1999: fig. 6; Archivo Soprintendenza di Palermo)

cumentan mayormente individuos infantiles acompañados de una gran cantidad de jóvenes ovicapridos (Di Salvo et al., 2012). Esta misma asociación de tumba de adultos con restos de bóvidos también se registra en Morgantina, donde fueron depositados los restos de una cornamenta de buey encima de los restos de un hombre adulto, concretamente en las ingles (Leighton, 1993: 108).

El vínculo establecido entre adultos, especialmente hombres, y bóvidos se observa de manera clara en algunas ánforas de mesa, especialmente en aquella en la que se presenta un personaje montando a caballo tocado por unas cornamentas. Pero también en el enocoe "de pulpo" y en la figurilla de arcilla donde, como hemos visto anteriormente, aparece representado un hombre adulto con pene erecto y cornamentas [7]. Esta reiterada asociación sugiere que determinados hombres adultos construyeron y materializaron su poder a través de una clara conexión con los bueyes, animales con los que no solo compartirían unos mismos espacios y temporalidades cotidianas, sino también ciertas características.

Asimismo, estos materiales también nos permiten evidenciar la existencia de relaciones entre animales y humanos en términos de transformación, ya que los personajes representados sufren un cambio físico mediante la incorporación de elementos animales a sus corporalidades. Ejemplo de esta modificación podría ser el exvoto de hueso en forma de pierna de buey documentado en la acrópolis cuya propia morfología y tipología de la pieza indican su posible uso utilizada a modo de decoración corporal. De manera más clara, esta transformación también se evidencia en la forma de pintar las manos de algunas figuraciones antropomórficas. Este es el caso de las manos de la figura de la enocoe "pulpo", cuyos dedos están desproporcionados respecto al cuerpo asemejándose más a pezuñas animales que a manos humanas. Esta misma transformación se identifica también en otro enocoe proveniente de Monte lato, donde aparece representado pintado un personaje antropomorfo con las manos y los dedos muy exagerados (Isler, 1996).

En relación a esta fusión de rasgos humanos y animales cabe señalar las representaciones que decoran una crátera de procedencia y actual paradero desconocida (Vasallo, 1999) [8]. En ella se observan cinco seres híbridos con cornamenta en la cabeza y pezuñas a modo de manos junto a un ave. La identidad fluida de estos seres híbridos muestra cómo las fronteras entre los humanos y los animales no se definen por igual en todas partes y que las esencias de los cuerpos animales y humanos no tienen siempre límites claros, diferenciándose así de nuestro contexto cultural occidental (Miracle y Boriç, 2008; Andersson et al., 2014).

El repertorio visual de los bóvidos nos muestra cómo la interacción con los humanos no solo se consigue mediante la agregación de partes de los animales a los cuerpos humanos -como ejemplifica el arte corporal-, sino también a través de alteraciones sensoriales. Estas últimas evidenciadas 
a partir de la ingesta de alimentos almacenados o consumidos en cerámicas con representaciones bovinas, pero también a través de determinadas danzas rituales. De hecho, el desarrollo de bailes puede inferirse a partir de las gestualidades de los personajes de los enocoes (rodillas flexionadas y manos alzadas), así como también por la composición del grupo de figuras híbridas que decora la crátera actualmente perdida, donde los personajes están dispuestos siguiendo un patrón de brazos alternado. Esta técnica de representación es un recurso común en diferentes casos de arte en la antigüedad para plasmar en soporte bidimensional movimientos rítmicos (Garfinkel, 2003). Cabe destacar, para finalizar, que esta fusión de ambos seres implica una relación de igualdad entre animales y humanos que, seguramente, tendría lugar en momentos y lugares concretos, por ejemplo, en las celebraciones periódicas que tendrían lugar en las acrópolis donde ciertas ceremonias serían desarrolladas únicamente por ciertos hombres adultos.

\section{Conclusiones}

El caso de Polizzello da cuenta de las complejas relaciones entre animales y humanos. Las imágenes de bucráneos y seres híbridos en el repertorio visual de esta comunidad ejemplifican perfectamente como ciertos grupos humanos (adultos masculinos) se constituyen como personas a través de la transferencia de algunas características de los bovinos. Durante este proceso se pone de manifiesto la agencia de estos animales, lo que permite que estos puedan ser definidos como personas-animales que no solo interactúan con las personas-humanas, sino que también participan en sus dinámicas sociales, tanto en ámbitos cotidianos como en rituales. Con ello, creemos que se rompe la visión antropocéntrica en la que, lejos de enfatizar el valor de los animales como seres vivos, se transciende su corporalidad para convertirlos en entes abstractos de carácter divino o simbólico. En definitiva, consideramos que estudiar la visualidad artística de determinados animales considerando su valor como agentes sociales es una estrategia adecuada para explorar de qué maneras los límites entre animales y humanos no son fijos ni rígidos, sino fluidos y permeables.

\section{Agradecimientos}

Los resultados preliminares de este trabajo fueron presentados inicialmente en las V Jornadas de Arqueología del IUHJW de la Universitat Pompeu Fabra en diciembre de 2016 bajo el título "More than fuel: food and ritual in domestic life», y en la sesión del EAA titulada «Animal representations in the past», en septiembre de 2018. Agradecemos a los participantes sus sugerencias. Vaya nuestro reconocimiento también a los revisores del artículo, cuyos comentarios han mejorado, sin duda, la publicación. En cuanto a las imágenes queremos agradecer a Stefano Vassallo, Caterina Trombi, Gabriella Sciortino y la Soprintendenza di Palermo, así como también a los profesores Giachimo Falsone y Robert Leighton.

\section{Notas}

1 Este artículo se enmarca en el proyecto de investigación «HESTIA: Comidas, cocinas y prácticas de consumo cotidiano en espacios coloniales mediterráneos (s. VIII-V a. C.)» (HAR2015-69842-P).

2 Cabe señalar que las poblaciones pertenecientes a la cultura de Thapsos, básicamente aquellas asentadas en el área oriental de la isla, establecen contactos culturales con grupos procedentes del Mediterráneo oriental, principalmente de Chipre y el Egeo, mostrando relaciones sociales y de intercambio complejas (Karageorghis 2005: 93-97).

\section{Bibliografía}

AZARA, Pedro (2002), «El becerro de oro. El imaginario del toro en el Mediterráneo antiguo», en ATHANASSOPOULO, Sapho, AZARA, Pedro, NICOLAU, Antoni y TZEDAKIS, Yannis (dirs.), Toros. Imagen y Culto en el Mediterráneo antiguo, Institut de Cultura, Barcelona, pp. 28 -94. BOYD, Bryan (2017), «Archaeology and Human-Animal Relations. Thinking through Anthropocentrism», Annual Review of Anthropology, n. ${ }^{\circ}$ 46, pp. 299-316. 
BORIĆ, Dusan (2013), «Theater of Predation: Beneath the Skin of Göbekli Tepe Images», en WATTS, Christopher (ed.), Relational Archaeologies: Humans, Animals, Things, Routledge, New York, pp. 42-64.

BORIĆ, Dusan, HARRIS, Oliver J. T., MIRACLE, Preston y ROBB, John (2013), «The limits of the body», en ROBB, John and HARRIS, Oliver, J. T. (eds.), The Body in History. Europe from the Paleolithic to the Future, Cambridge University Press, Cambridge, pp. $32-63$.

CASTELLANA, Giuseppe (1984), «Tre indagini sulla cultura indigena in Sicilia», en Studi in onore di G. Maetzke, G. Bretschneider, Roma, pp. 221-227.

CEDERHOLM ANDERSSON, Erika, BJÖRCK, Amelie, JENNBERT, Kristina and LÖNNGREN, Ann-Sofie (eds.) (2014), Exploring the Animal Turn: Human-animal relations in Science, Society and Culture. Lund University, Lund.

CLOTTES, Jean y LEWIS-WILLIAMS, David (2010), Los chamanes en la Prehistoria, Ariel, Barcelona.

CULTRARO, Massimo (2012), «Quis Deus? Su alcune rappresentazioni di carattere cultuale nella Sicilia dell’Età del Ferro», en NIZZO, Valentino y LA ROCCA, Luigi (eds.), Antropologia e archeologia a confronto: rappresentazioni e pratiche del sacro, E.S.S. Editorial Service System, Roma, pp. 387-399.

CULTRARO, Massimo e CRISPINO, Anita (2015), «Preesistenze del bestiario orientalizzante: il contributo della Sicilia», en BIELLA, Maria Cristina e GIOVANELLI, Enrico (eds.), Nuovi studi sul bestiario fantastico di età orientalizzante nella Penisola italiana, Tangram Edizione Scientifiche, Trento, pp. 41-62.

De MIRO, Ernesto (1988), "Polizzello, centro della Sicania», Quaderni dell'Istituto di Archaeologia della Facoltà di Lettere e Filosofia della Università di Messina, n. ${ }^{\circ}$, pp. 25-42.

DEMARRAIS, Elizabeth and ROBB, John (2013), «Art makes society: an introductory visual essay», World Art, n. ${ }^{\circ}$ 3: 1, pp. 3-22.

Di ROSA, Maurizio (1999), «Studio archeologico dei resti faunistici rinvenuti a Colle Madore», en VASSALLO, Stefano (ed.), Colle Madore: un casi di ellenizzazione in terra sicana, Regione Siciliana-Beni Culturali, Palermo, pp. 255-266.

- (2003), «I resti faunistici», en SPATAFORA, Francesca (ed.), Monte Maranfusa. Un insediamento nella media Valle del Belice, Regione Siciliana-Beni Culturali, Palermo, pp. 397-413.

Di SALVO, Rosaria, MESSINA, Andrea, SCHIMMENTI, Vittoria, SINEO, Luca e MANNINO, Marcello (2012), "Studio antropologico sull gruppo umano di Polizzello (Mussomeli-CL)», en TUSA, Sebastiano (ed.), Dai Ciclopi agli Ecisti. Società e Territorio nella Sicilia preistorica e protostorica, Edizioni I.I.P.P, pp. 989-999.

FALSONE, Gioachimo (1980), «Per salvare Entella», Sicilia Archeologica, XIII, 43, pp. 21-26.

FALSONE, Gioachimo, DI NOTO, Carla e BECKER, Martin (1993), «Due tombe arcaiche da Entella», en NENCl, Giuseppe (ed.), Alla ricerca di Entella, Scuola Normale di Pisa, Pisa, pp. 157-194.

FERRER, Meritxell (2010), «Raciones de Solidaridad: mujeres, alimentos y capeduncolas en Sicilia occidental (s. VII-V a. C.)», Saguntum Extra, n. ${ }^{\circ}$, pp. 209-218.

- (2013), «Feasting the Community: Ritual and Power on the Sicilian Acropoleis (10th-6th centuries BC)», Journal of Mediterranean Archaeology, n. ${ }^{\circ}$ 26: 2, pp. 211-234.

FIORENTINI, Graziella (1999), «Necropoli dei centri indigeni della Valle del Platani: organizzazione, tipologie, aspetti rituali», en BARRA BAGNASCO, Maria, DE MIRO, Ernesto e PINZONE, Antonio (eds.), Magna Grecia e Sicilia: stato degli studi e prospettive di ricerca, Dipartamento di Scienze delle Antichità dell'Università degli Studi di Messina, Messina, pp. 195-201.

FOWLER, Chris (2004), The Archaeology of Personhood. An Anthropological Approach, Cambridge University Press, Cambridge.

- (2008), «Fractal bodies in the past and the present», en BORIĆ, Dusan and ROBB, John (eds.), Past Bodies. Body-Centered Research in Archaeology, Oxbow Books, Oxford, pp. 47-57.

GARFINKEL, Yosef (2003), Dance at the Dawn of Agriculture, Texas University Press, Austin.

GELL, Alfred (1998), Art and Agency. Clarendon Press, Oxford.

GITTINS, Erica (2013), «The archaeology of becoming the human animal», Society \& Animals, n. ${ }^{\circ} 21: 2$, pp. $120-33$.

GUZZONE, Carla (2006), Sikania. Tesori archeologici dalla Sicilia centro-meridionale (secoli XIII-VI a. C.), Giuseppe Maimone Editore, Palermo.

GUZZONE, Carla, PALERMO, Dario e PANVINI, Rosalba (2009), Polizzello: Scavi del 2004 nell'area del santuario arcaico dell'acropoli, Regione siciliana-Beni Culturali, Palermo. 
HARRISON-BUCK, Eleanor and HENDON, Julia A. (2018), «An Introduction to Relational Personhood and Other-than-Human Agency in Archaeology", en Relational Identities and Other-than-Human Agency in Archaeology, University Press of Colorado, Louisville, pp. 3-28.

HILL, Erica (2011), «Animals as Agents: Hunting Ritual and Relational Ontologies in Prehistoric Alaska and Chukotka», Cambridge Archaeological Journal, n. ${ }^{\circ} 21:$ 3, pp. 407-426.

- (2013), «Archaeology and Animal Persons. Toward a Prehistory of Human-Animal Relations», Environment and Society: Advances in Research, n. ${ }^{\circ}$, pp. 117-136.

- (2018), «Personhood and Agency in Eskimo Interactions with Other-than-Human», en HARRISON-BUCK, Eleanor and HENDON, Julia A. (eds.), Relational Identities and Other-than-Human Agency in Archaeology, University Press of Colorado, Louisville, pp. $29-50$.

HNATIUK, Tara (2003), «Preliminary faunal report on the Acropolis of Monte Polizzo, 2003. Appendix 2», en MORRIS, Ian, JACKMAN, Trinity, GARNARD, Brien, BLAKE, Emma and TUSA, Sebastiano (eds.), Stanford University excavations on the acropolis of Monte Polizzo, Sicily 4: preliminary report on the 2002 season. Memoirs of the American Academy in Rome 48, Istituto italiano d'arti grafiche, Roma, pp. 247-253.

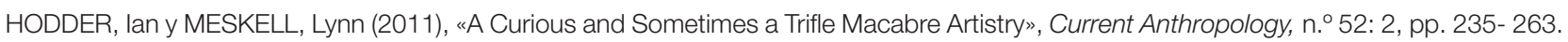
ISLER, Hans Peter (1996), «Monte lato: la ventiseiesima campagna di scavo», Sicilia Archeologica, 90-92.

KARAGEORGHIS, Vassos (2005), «The Phoenician Cyprus», en CELESTINO, Sebastián y JIMÉNEZ, Javier (eds.), El Periodo orientalizante. Actas del III Simposio Internacional de Arqueología de Mérida. Protohistoria del Mediterráneo occidental, Anejos de Archivo Español de Arqueología, n. ${ }^{\circ} X X X$, pp. 31-46.

KNAPPET, Carl (2005), Thinking Through Material Culture, University of Pennsylvania Press, Philadelphia.

LEIGHTON, Robert (1993), Morgantina Studies VI: the protohistoric settlement on the Cittadella, Princeton University Press, Princenton.

- (1999), Sicily before the History, Cornell University Press, New York.

MIRACLE, Preston and BORIĆ, Duran (2008), «Bodily beliefs and agricultural beginnings in Western Asia: animal-human hybridity re-examined», en BORIĆ, Dusan and ROBB, John (eds.), Past Bodies. Body-Centered Research in Archaeology, Oxbow Books, Oxford, pp. 101-113.

MÜHLENBOCK, Christian (2008), Fragments from a Mountain Society. Tradition, Innovation and Interaction at Archaic Monte Polizzo, Sicily, Gotarch series C, Göteborg.

PALERMO, Dario, TANASI, Davide y PAPPALARDO, Eleanora (2009), «Polizzello. Le origini del Santuario», en CONGIU, Marina, MICCHË, Calogero e MODEO, Simona (eds.), EIS AKRA. Insediamenti di altura in Sicilia dalla Preistoria al III sec. A. C., Salvatore Sciascia Editore, Palermo, pp. 47-88.

PANVINI, Rosalba (2003), Caltanissetta. I/ Museo Archeologico, Regione Siciliana-Beni Culturali, Palermo.

RITVO, Harriet (2007), «On the animal turn», Daedalus, n. ${ }^{\circ}$ 136: 4, pp. 118-122.

ROBB, John and HARRIS, Oliver. J. T. (2013), «Body worlds and their history: some working concepts», en The Body in History. Europe from the Paleolithic to the Future, Cambridge University Press, Cambridge, pp. 7- 31.

RUSSELL, Nerisa (2012), Social zooarchaeology. Humans and animals in Prehistory, Cambridge University Press, New York.

SANCHIDRIÁN, José Luis (2018), Manual de arte prehistórico, Ariel, Barcelona.

SHAPLAND, Andrew (2010), «Wild Nature? Human-Animal Relations on Neopalatial Crete», Cambridge Archaeological Journal, n. ${ }^{\circ} 20: 1$, pp. 109-127.

THOMAS, J. (2007). «Archaeology's humanism and the materiality of the body», en INSOLL, Timothy (ed.), The Archaeology of Identities: a Reader, Routledge, London and New York, pp. 211-224.

TROMBI, Caterina (2003), «Considerazioni sui vasi indigini con applicazioni plastiche della Sicilia Occidentale (VII-V sec. A. C.)», en Archeologia del Mediterraneo. Studi in onore di Ernesto De Miro, L'Erma di Bretschneider, Roma, pp. 693-710.

VASALLO, Stefano (1999), «Un cratere figurato indigeno nella testimonianza di un disegno», Sicilia Archeologica, n. ${ }^{\circ}$ XXXII, 97, pp. $211-216$. WEISMANTEL, Mary y MESKELL, Lynn (2014), «Substances: "Following the Material” through two prehistoric cases», Journal of Material Culture, n. ${ }^{19:}$ 3, pp. 233- 251. 